\title{
Excess Factor VIII: A Common Cause of Hypercoagulability
}

\author{
Robert S. Bobrow, MD
}

Background: Elevations of coagulation factor VIII have recently been described in significant numbers of patients with venous thromboembolism (VTE) previously thought to have had an "idiopathic" event. Three patients from a family practice are presented with recurrent VTE and increased factor VIII levels.

Method: The case histories and results of laboratory tests were reviewed.

Results: The 3 patients had no other clear coagulopathy. In 2 of the 3, the increase was confirmed with a second reading.

Conclusions: Factor VIII assay should be considered in the work-up of idiopathic, recurrent VTE. Long-term anticoagulation may be appropriate in this setting. ( $\mathrm{J}$ Am Board Fam Pract 2005;18:147-9.)

Venous thromboembolism (VTE) is seen frequently in primary care. With the advent of sophisticated laboratory testing, at least half of previously idiopathic cases can be found to have a coagulation disorder. ${ }^{1}$ Although the heritable factor V Leiden mutation has been believed to be the most common of these $(5 \%$ of the white population is heterozygous for the disorder), ${ }^{2}$ increased activity of factor VIII has recently emerged as a relatively common identifiable cause of hypercoagulability. In 1995, Koster et $\mathrm{al}^{3}$ studied 301 VTE patients without cancer and matched control subjects and found a dose-response relationship between factor VIII concentration and risk of thrombosis; subjects with factor VIII activity above 150\% (150 IU/dL) represented $25 \%$ of the sample and had an adjusted odds ratio for VTE of 4.8. Kraaijenhagen et $\mathrm{al}^{4}$ found a $33 \%$ prevalence of factor VIII activity above $175 \%$ (the 90th percentile) in recurrent VTE cases, and concluded that such elevated plasma levels were a significant, prevalent, independent, and dose-related risk factor. Kyrle et $\mathrm{al}^{5}$ followed patients with a first episode of VTE after anticoagulants had been discontinued and found patients above the 90th percentile for plasma factor VIII levels had a 6.7 -fold relative risk of recurrence compared with those with lower levels. Elevated factor VIII levels have been found to persist over time $^{4,6}$ and to be independent of the acute phase

Submitted, revised, 4 October 2004

From the Department of Family Medicine, Stony Brook University, Stony Brook, NY. Address correspondence to Robert S. Bobrow, 20 Pinewood Dr., Commack, NY 11725 (e-mail: rbobrow@notes.cc.sunysb.edu). response. ${ }^{6-8}$ (The studies above nevertheless remeasured factor VIII several months after the VTE event.)

This is a report of 3 cases of thromboembolism not associated with conventional risk factors (trauma, cancer, or immobility). The patients were found to have elevated factor VIII activity without other evidence of a hypercoagulable state.

\section{Case 1}

A 40-year-old man with recurrent attacks of shortness of breath and syncope was diagnosed with multiple distal pulmonary emboli by computed tomographic angiography. There was neither a past history nor a family history of thromboembolic disease. He was a smoker and took paroxetine and trazodone. Venous duplex scans of both legs were negative for deep vein thrombosis (DVT). Results of laboratory tests are shown in Table 1. Lupus anticoagulant screen ratio was initially weakly positive, but the results of a confirmatory test (screen/ confirm ratio) were negative, and phospholipid dependence could not be confirmed. Anticardiolipin IgM at 13 fell into the laboratory's "indeterminate" range (12.5-20 MPL units; $1 \mathrm{MPL}$ unit $=1 \mu \mathrm{g}$ of affinity-purified $\operatorname{IgM}$ anti-cardiolipin antibodies from an original index serum sample), but low-level IgM antibodies occur with other conditions and are not associated with thromboembolism. ${ }^{9}$ All other coagulation factors were unremarkable, except for a markedly elevated factor VIII activity. The patient was on heparin and warfarin at this time. A second factor VIII assay, which was performed on an outpatient basis a year later, by a different lab, was normal at $126 \%$. 


\begin{tabular}{|c|c|c|c|c|}
\hline & Patient 1 & Patient 2 & Patient 3 & $\begin{array}{c}\text { Reference } \\
\text { Range }\end{array}$ \\
\hline Age/sex & $40 / \mathrm{M}$ & $63 / \mathrm{F}$ & $45 / \mathrm{M}$ & \\
\hline Presenting problem & $\mathrm{PE}^{*}$ & $\mathrm{PE} / \mathrm{DVT}$ & DVT & \\
\hline Platelets & 143,000 & 273,000 & 236,000 & \\
\hline Factor V Leiden mutation & $\mathrm{NP}$ & NP & NP & \\
\hline Prothrombin gene mutation & NP & NP & NP & \\
\hline Activated protein $S$ & 129 & 76 & 116 & $82 \%$ to $151 \%$ \\
\hline Activated protein $\mathrm{C}$ & 78 & $11 \dagger$ & 72 & $65 \%$ to $122 \%$ \\
\hline Antithrombin III activity & 71 & 112 & 66 & $85 \%$ to $130 \%$ \\
\hline Antithrombin III antigen & 280 & & 215 & 191 to $369 \mathrm{mg} / \mathrm{L}$ \\
\hline Anti-cardiolipin IgG & 6 & 10 & 18 & $<15:-15$ to $20: \pm$ \\
\hline Anti-cardiolipin IgM & 13 & 15 & 11 & $<12.5:-12.5$ to $20: \pm$ \\
\hline Lupus anticoagulant screen ratio & 1.36 & & 1.50 & $<1.20$ \\
\hline Protein S antigen (total) & 144 & 65 & 153 & $72 \%$ to $152 \%$ \\
\hline Protein $\mathrm{C}$ antigen & 81 & 60 & 61 & $76 \%$ to $158 \%$ \\
\hline Factor $\mathrm{X}$ antigen & & 52 & 98 & $70 \%$ to $140 \%$ \\
\hline Homocysteine & & 10.9 & 11.9 & \\
\hline Factor IX & & 66 & & \\
\hline \multirow[t]{2}{*}{ Factor VIII (done twice) } & 276 & 239 & 247 & $50 \%$ to $150 \% \ddagger$ \\
\hline & $126 \$$ & 221 & 329 & \\
\hline
\end{tabular}

* PE, pulmonary emboli; DVT, deep vein thrombosis; NP, not present.

$\dagger$ Believed to be secondary to concomitant warfarin.

$\ddagger$ Percentage (\%) is the same as international units/deciliter (IU/dL).

$\$$ Performed at a different laboratory; all others done by Stony Brook University Hospital Laboratory.

\section{Case 2}

A 63-year-old woman was admitted for a pulmonary embolism; on duplex scanning of the lower extremities, 2 clots were also found in the left leg. She had a history of one miscarriage and 4 live births. Her brother had a myocardial infarction at age 39, and her father died of a myocardial infarction at age 63. She also had chronic obstructive pulmonary disease and hypertension. She had quit smoking 4 years before presentation. Results of laboratory tests are summarized in Table 1 . The factor VIII elevations were the most striking abnormality. These were found several months after the embolism as part of a coagulopathy work-up; the 2 levels were taken 11 days apart to confirm persistent elevation. The patient was on warfarin at the times of testing.

\section{Case 3}

A 45-year-old man was admitted for a symptomatic (painful) left leg DVT. He had had a DVT of the same leg at age 16 . He was a smoker. His history included schizophrenia and his medications were omeprazole, benztropine, divalproex, and olanzap- ine. There was no family history of thromboembolic phenomena. Results of laboratory tests are summarized in Table 1. Lupus anticoagulant screen ratio, initially increased, could not be confirmed with a mixing study (screen/confirm ratio was negative). Anticardiolipin IgG fell into the laboratory's "indeterminate" range and would not meet the criteria for antiphospholipid antibody syndrome. ${ }^{10} \mathrm{~A}$ factor VIII level that had been obtained on an outpatient basis about 1 year before the hospitalization, in the course of a coagulopathy workup, was elevated at $326 \%$. During the admission, it was $247 \%$. The patient was on enoxaparin at the times of testing.

\section{Discussion}

Factor VIII levels above normal ( $>150$ IU/dL) can be found in $11 \%$ of the general adult population. ${ }^{11}$ It is also a significant VTE risk factor for children. ${ }^{12}$ It has only recently been appreciated that this entity may account for a significant proportion of idiopathic hypercoagulable states. In clinical practice, most people being worked up for recur- 
rent VTE will be taking anticoagulation agents, but this should not affect the results of factor VIII assays. (The Stony Brook University laboratory uses a partial thromboplastin-based assay that is unaffected by anticoagulants that patients may be taking.) Patients 2 and 3, above, had persistent elevations in factor VIII, with at least one result separated in time from the acute VTE event. This could not be demonstrated with patient 1 , although the second assay was done at a different lab.

\section{Conclusion}

Factor VIII excess is a recently described, apparently common, and under-recognized cause of VTE. Some reviews ${ }^{1,13}$ of hypercoagulability do not mention factor VIII excess. It persists over time, may be genetic, ${ }^{4,8}$ and is associated with about a 6-fold increase in VTE events. ${ }^{3,5}$ In one study, patients with levels above the 90th percentile (>234 IU/dL) had a 37\% likelihood of recurrence of a thromboembolic event within 2 years. ${ }^{5}$ Our understanding of this entity is evolving; guidelines for treatment and for frequency and methodology of testing do not yet exist. It does seem that patients with recurrent or unusual VTE who have persistent elevations of factor VIII activity ( $>150 \%)$ may be candidates for long-term prophylaxis with warfarin.

I thank Lisa Cupit, MD, and Peter L. Perrotta, MD, for assistance.

\section{References}

1. Locke CF and Evans NC. Evaluating idiopathic venous thromboembolism: what is necessary, what is not. J Fam Pract 2003;52:770-6.

2. Ridker PM, Militich JP, Hennekens CH, Buring JE. Ethnic distribution of factor V Leiden in 4047 men and women. Implications for venous thromboembolism screening. JAMA 1997;277:1305-7.
3. Koster T, Blann AD, Briet E, Vandenbroucke JP, Rosendaal FR. Role of clotting factor VIII in effect of von Willebrand factor on occurrence of deep-vein thrombosis. Lancet 1995;345:152-5.

4. Kraaijenhagen RA, in't Anker PS, Koopman MM, et al. High plasma concentration of factor VIIIc is a major risk factor for venous thromboembolism. Thromb Haemost 2000;83:5-9.

5. Kyrle PA, Minar E, Hirschl M, et al. High plasma levels of factor VIII and risk of recurrent thromboembolism. N Engl J Med 2000;343:457-62.

6. O'Donnell J, Mumford AD, Manning RA, Laffan M. Elevation of FVIII: $\mathrm{C}$ in venous thromboembolism is persistent and independent of the acute phase reaction. Thromb Haemost 2000;83:10-3.

7. O’Donnell J, Tuddenham EG, Manning R, Kemball-Cook G, Johnson D, Laffan M. High prevalence of elevated factor VIII levels in patients referred for thrombophilia screening: role of increased synthesis and relationship to the acute phase reaction. Thromb Haemost 1997;77:825-8.

8. Kamphuisen PW, Eikenboom JC, Vos HL, et al. Increased levels of factor VIII and fibrinogen in patients with venous thromboembolism are not caused by acute phase reactions. Thromb Haemost 1999;81:680-3.

9. Asherson RA. Antiphospholipid antibodies and syndromes. In: Systemic lupus erythematosus, 2nd ed (Lahita RG, editor). New York: Churchill Livingstone; 1992. p. 587-635.

10. Levine JS, Branch DW, Rauch J. Antiphospholipid antibody syndrome. N Engl J Med 2002;346:75263.

11. Kim V, Spandorfer J. Epidemiology of venous thromboembolic disease. Emerg Med Clin North Am 2001;19:839-59.

12. Goldenberg NA, Knapp-Clevenger R, Manco-Johnson MJ. Elevated plasma factor VIII and d-dimer levels as predictors of poor outcomes of thrombosis in children. N Engl J Med 2004;351:1081-8.

13. Ridker PM. Inherited risk factors for venous thromboembolism: implications for clinical practice. Clin Cornerstone 2002;4:18-30. 